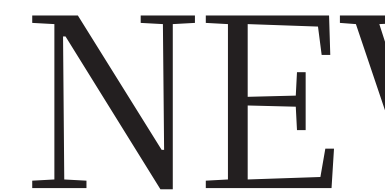

LAND USE Soviet-era cropland and a dilemma over food versus carbon sinks p.342
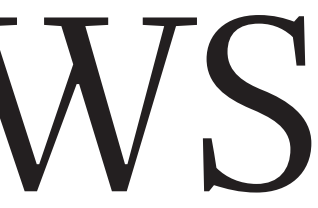
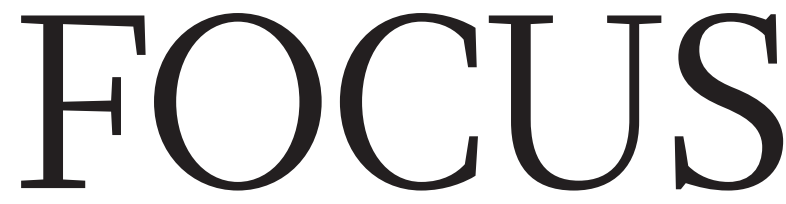

US FUNDING Foundation research support rises, but not for overheads $\mathbf{p . 3 4 3}$
YEAR IN REVIEW Twelve

months of science news at your fingertips p.344
NATURE'S 10 The people behind major science stories in 2013 p.357

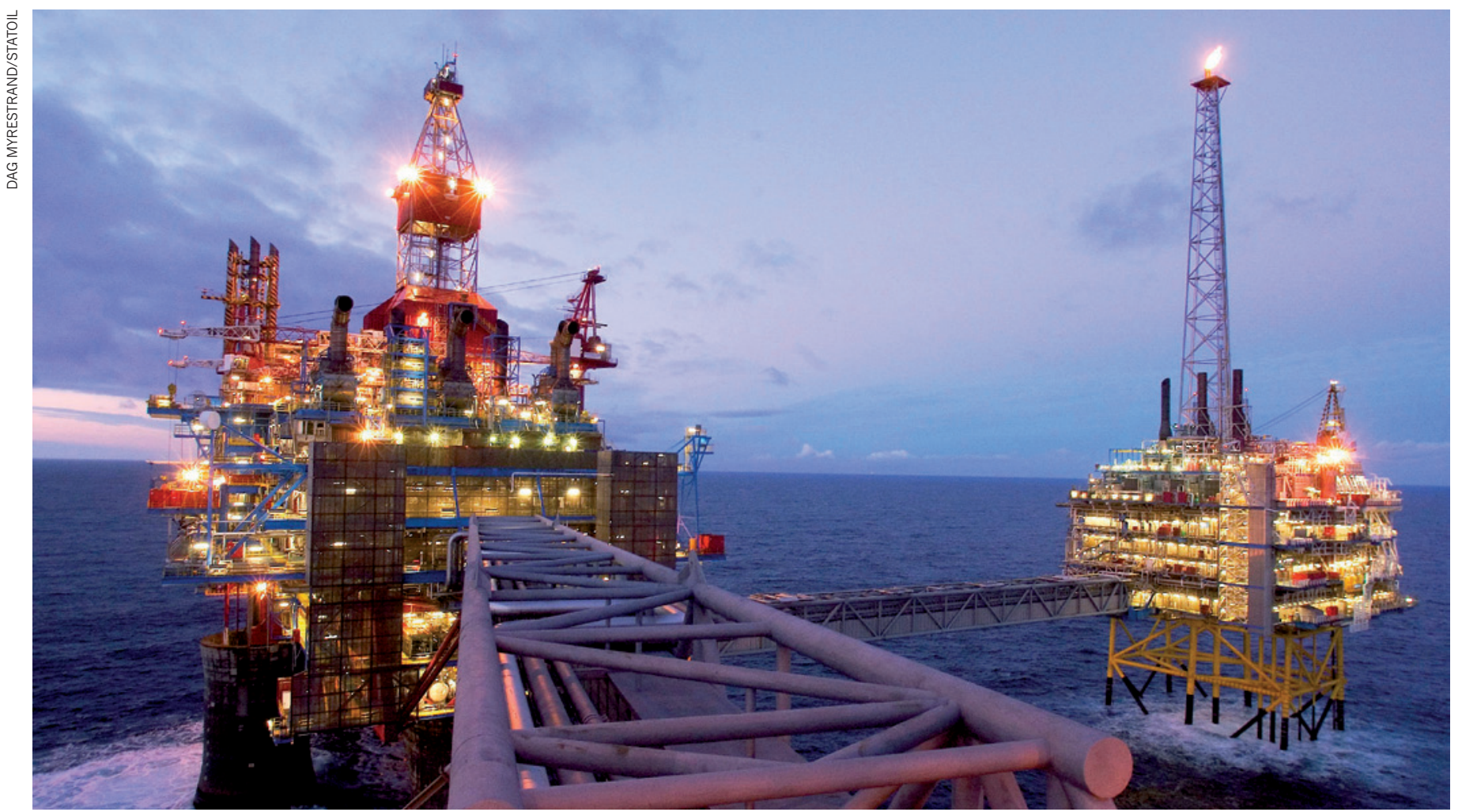

At the Sleipner field in the North Sea, waste carbon dioxide is separated from natural gas and injected into a rock formation 800 metres below the seabed.

\title{
Seabed scars raise questions over carbon-storage plan
}

Unexpected fractures above the world's biggest storage site could provide path for leaks.

\section{BY RICHARD MONASTERSKY}

$\mathrm{L}$ ike a porpoise on the prowl, the sleek submersible HUGIN tracks its prey with sonar chirps. But the hunter set loose in the waters of the North Sea is not pursuing fish - the robot is trawling for geological clues that could help to determine whether billions of tonnes of carbon dioxide can be stored below the sea floor for centuries, keeping it from warming the planet.

Now, the latest data from the autonomous underwater vehicle and other tools deployed by the European Commission's $€ 10$-million (US\$13.8-million) $\mathrm{ECO}_{2}$ research project suggest that the plan might not be so simple. The seabed is fractured and scarred more than researchers had appreciated - providing potential routes for $\mathrm{CO}_{2}$ to leak from subseabed reservoirs where it is currently being stored. "We are saying it is very likely something will come out in the end," says Klaus Wallmann, $\mathrm{ECO}_{2}$ coordinator and a marine geochemist at the GEOMAR Helmholtz
Centre for Ocean Research in Kiel, Germany. Such a conclusion could raise problems for the field of carbon capture and storage, especially in Europe, where any suggestion of leakage could reduce public support for the strategy. But $\mathrm{ECO}_{2}$ researchers say that evidence from oil-industry carbon-storage efforts already under way in the North Sea and Barents Sea suggests no hint of leakage, and that there would be little cause for concern even if there were. "We are very confident that if it were to occur, the rates would be low and the impact would 


\section{GAS TANK}

Researchers have found fractures near a $\mathrm{CO}_{2}$ storage site, suggesting that the gas might someday be able to leak out in small amounts.

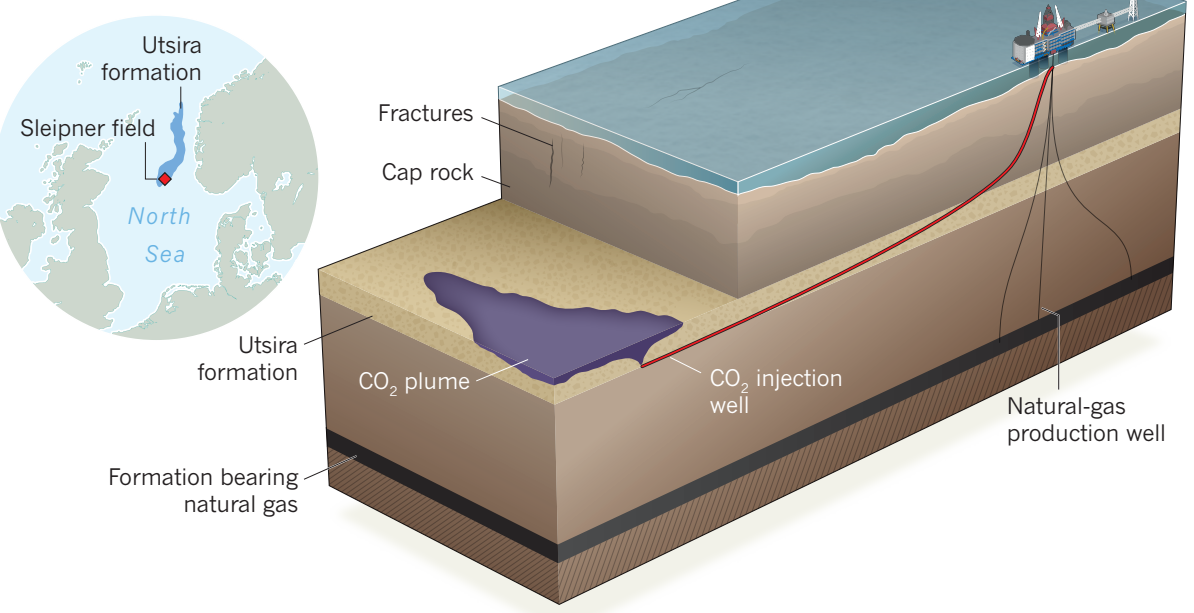

- be minimal," says Wallmann, who presented the findings of the $\mathrm{ECO}_{2}$ team on 9 December at a meeting of the American Geophysical Union in San Francisco, California.

Oil companies have long injected $\mathrm{CO}_{2}$ into underground formations to enhance oil production, but the $\mathrm{ECO}_{2}$ project is studying sites where the gas is pumped below the sea floor to keep it out of the atmosphere. One of the biggest operations is in the Sleipner natural-gas field in the North Sea, run by the energy company Statoil, headquartered in Stavanger, Norway.

Since 1996, the company has separated $\mathrm{CO}_{2}$ gas from the desired hydrocarbons and reinjected up to 1 million tonnes of $\mathrm{CO}_{2}$ a year into the Utsira formation, a layer of porous sandstone more than 800 metres below the sea floor (see 'Gas tank'). The giant formation, which covers an area of 24,000 square kilometres, has the potential to hold 600 billion tonnes of disposed $\mathrm{CO}_{2}$. According to Statoil's website, $\mathrm{CO}_{2}$ in the Utsira is safely contained under "gas-tight cap rock and cannot seep into the atmosphere".

Although the company has rich data about the Utsira formation, less is known about the overlying sedimentary layers. $\mathrm{ECO}_{2}$ researchers have deployed HUGIN and other tools to fill in the details, using an advanced sonar system and a seismic profiler that sent strong acoustic pulses below the sea floor to reveal hidden geological structures.

The data reveal that the upper sedimentary layers hold many natural scars that might serve as conduits for $\mathrm{CO}_{2}$ release from the Utsira.
At a site 25 kilometres north of the Sleipner injection well, HUGIN found a 3-kilometrelong fracture that is 10 metres wide in places, and runs 150-200 metres deep. Samples of fluids collected within the fracture suggest that methane and fresh water are leaking out from lower layers, says Karin Landschulze, a graduate student in geophysics at the University of Bergen, Norway.

\section{LEAK IMPACT}

Because the fracture is so far from the injection site, the disposed $\mathrm{CO}_{2}$ is unlikely to reach it any time soon, say $\mathrm{ECO}_{2}$ researchers: since 1996, the $\mathrm{CO}_{2}$ has spread in a plume and now reaches 3 kilometres north of the injection well. But finding such a large and unexpected fracture in the region raises questions, says Wallmann. "We don't know how it formed, when it formed, and why it formed," he says.

The researchers also discovered smaller vertical features, which they call chimneys and pipes, running through the sedimentary layers. One of these is only about 5 kilometres from the Sleipner $\mathrm{CO}_{2}$ plume, and it reaches all the way down into the Utsira formation.

The discovery of so many potential leakage paths in the few sites examined has scientists reconsidering how well-contained the Utsira reservoir really is. "We might have to appreciate that there is a much greater chance for some $\mathrm{CO}_{2}$ to leak out," says Stefan Bünz, a marine geologist at the University of Tromsø in Norway, who participated in the $\mathrm{ECO}_{2}$ experiment.
Yet neither the $\mathrm{ECO}_{2}$ project nor Statoil has found any indications that $\mathrm{CO}_{2}$ has leaked from Sleipner in its 17 years of operation. Furthermore, the $\mathrm{ECO}_{2}$ team has tested the likely impact of leaks, should they occur, by injecting up to 150 kilograms of $\mathrm{CO}_{2}$ a day just above the sea floor near Sleipner. They found that the $\mathrm{CO}_{2}$ completely dissolved within the lower few metres of water, rapidly converting to bicarbonate and dispersing. Only a small amount of the injected gas may have reached the atmosphere, says Wallmann.

The researchers also studied a spot in the Mediterranean Sea where natural vents release about 1 tonne of $\mathrm{CO}_{2}$ a day. They found that the gas, which acidifies nearby waters, kills off many organisms within a small, 10-metre zone around the vent and reduces species diversity within a radius of about 100 metres, but that effects beyond that distance are limited.

A leak would be much more troubling from a public-relations standpoint, says Landschulze, because carbon capture and storage has been promoted in Europe as being safe. "It would be a disaster for public opinion," she says.

Yet because offshore disposal happens far from population centres, it has some advantages over onshore storage. Germany, Spain and Norway are each running onshore pilot experiments in which they have injected tens of thousands of tonnes of $\mathrm{CO}_{2}$ into reservoirs underground, but some people have expressed concern about large-scale disposal on land. "I think it's easier to work offshore in the sense that the public perception is not ready for $\mathrm{CO}_{2}$ storage in their backyards," says hydrogeologist Pascal Audigane of the French Geological Survey in Orléans, who manages a $€ 5$-million carbon-storage project in an underground lab in Switzerland.

In the end, the biggest impediments to subseabed $\mathrm{CO}_{2}$ disposal are probably not leakage, but economics. Disposal makes sense at Sleipner, because the $\mathrm{CO}_{2}$ has to be separated from natural gas for commercial purposes anyway, and Norway would impose a tax on Statoil if the waste gas were released. But the price of carbon emissions would have to rise in other countries before it becomes worthwhile to pump waste $\mathrm{CO}_{2}$ from power plants and other sources on land to offshore injection sites. The chances of that happening soon may be slim, but carbonstorage researchers are carrying on with their work in case countries decide to push forwards with major cuts in greenhouse-gas emissions.
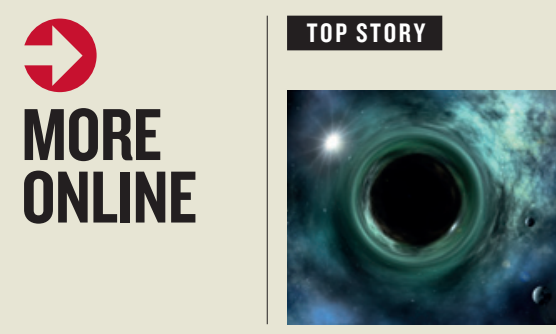

Simulation backs string theory's holographic Universe go.nature.com/ uvggva

\section{MORE NEWS}

- Water seems to flow freely near Martian equator go.nature.com/9zzlzw

- Twitter popularity does not predict citations go.nature.com/xkwyei

- Caribou genetics may impair the animals' ability to cope with climate change go.nature.com/mkdohf

\section{NATURE PODCAST}

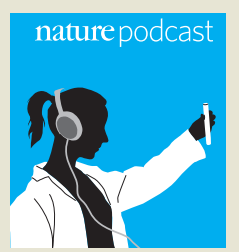

Neanderthals, the science of pickles and a satirist's look at the year in science nature.com/ nature/podcast 